\title{
KARAKTERISTIK, MOTIVASI DAN KEPUASAN WISATAWAN NUSANTARA YANG BERKUNJUNG KE DAYA TARIK WISATA CITY TOUR DENPASAR
}

\author{
Pius Tenouye \\ I Wayan Suardana \\ Ni Gusti Ayu Susrami Dewi \\ Email : yohanespiustenouye@gmail.com \\ PS. SI Industri Perjalanan Wisata \\ Fakultas Pariwisata UNUD
}

\begin{abstract}
This study aims to determine the characteristics, motivation and satisfaction of tourists who visit the tourist attraction city tour Denpasar. Research methods include: observation, questionnaires to 100 tourists, literature study and documentation and descriptive qualitative as the analysis techniques. The results showed that the characteristics of tourists dominated 81\% aged 15-30 years, $60 \%$ male, $79 \%$ are not married, university level education $71 \%, 77 \%$ students, $56 \%$ of the island of Java, resources through friends / family 36\%, 62\% ground transportation, hotel accommodations as a means of $65 \%$, frequency of visit to Bali $2-3$ times $75 \%$, 45\% choose to visit, type of visit $65 \%$, $65 \%$ of people who had been invited, organizers of $75 \%$. Furthermore, intrinsic motivation tourists dominated by indicators want to know the Balinese art with scale score of 4.21 (strong), while extrinsic motivation is dominated indicators admission fee affordable fascination with score of 4.20 (strong). In general, tourists are satisfied with the tourist attraction, and the indicator that dominates is the physical aspect of the form of security with score of 4.33 (very satisfied) and non-physical aspects of the hospitality and courtesy clerk with score of 4.97 (very satisfied). Through this research is expected the municipality, manager of a tourist attraction can improve the quality and attractiveness of city tour service in accordance with the characteristics, motivation and satisfaction of tourists so the frequency and the number of tourist arrivals increased evenly.
\end{abstract}

Keywords: Characteristic, Motivation, Satisfaction, Domestic Tourist, City Tour Denpasar.

\section{LATAR BELAKANG}

Provinsi Bali terbagi menjadi delapan kabupaten dan satu kota madya. Perkembangan pariwisata di Bali selaras dengan penataan potensi pariwisata semua kabupaten dan kodya. Salah satu kabupaten yang selama ini menjadi favorit wisatawan untuk dikunjungi adalah Kabupaten Badung. Kabupaten Badung dikenal dunia karena beberapa daya tarik wisatanya, seperti Kuta dan Nusa Dua. Kota Denpasar sebagai satusatunya kota madya yang dimiliki Bali saat ini mulai menggeliat menjadi destinasi wisata yang diminati oleh wisatawan.

Kota Denpasar yang terletak pada lokasi yang sangat strategis, maka sejak dini sangat diperlukan penataan potensi dan daya tarik wisata. Untuk mewujudkan atraksi wisata berupa keunggulan dan keunikan wisata dibandingkan kabupaten lain di Bali, maka Pemerintah Kota melalui Dinas Pariwisata Kota Denpasar menetapkan sembilan daya tarik wisata yang masing-masing memiliki potensi dan keunikan tersendiri ke dalam daya tarik wisata city tour Denpasar antara lain: 1) Lapangan I Gusti Made Ngurah Agung dan sekitarnya, 2) Patun Catur Muka, 3) Pura Jagatnatha, 4) Museum Bali, 5) Rute sepanjang Jl. Sugianyar, P. Buton, Jl. Sumatera, Jl. Hasanudin, Jl. G. Batur, Jl. G. Merpati, Jl. Setiabudi, Jl. Sutomo, Jl. Gajahmada dan Jl. Veteran, 6) Puri Agung Jrokuta, 7) Pura Maospahit, 8) Pasar Badung, dan 9) Hotel Inna Bali. City tour Denpasar merupakan salah satu strategi dari Pemerintah Kota Denpasar guna menarik minat wisatawan 
khususnya wisatawan nusantara untuk berkunjung ke Kota Denpasar.

Dari sembilan daya tarik yang ditetapkan melalui SK Walikota, terdapat empat daya tarik wisata city tour dengan tingkat kunjungan wisatawan yang cukup tinggi meliputi: Museum Bali, Monumen Bajra Sandhi, Desa Budaya Kertalangu, dan Pulau Serangan. Hal ini menarik bagi penulis untuk melakukan studi mengenai karakteristik, motivasi, dan kepuasan wisatawan nusantara yang berkunjung ke daya tarik wisata city tour Denpasar. Studi ini penting dilakukan agar nantinya Pemerintah Kota Denpasar dapat meningkatkan jumlah kunjungan ke empat daya tarik utama city tour yang dimiliki dan diharapkan mampu meningkatkan tingkat kunjungan wisatawan nusantara secara merata ke seluruh daya tarik wisata city tour.

\section{METODE}

Lokasi penelitian di Kota Denpasar terdiri dari empat objek penelitian yaitu Museum Bali, Monumen Bajra Sandhi Bali, Desa Budaya Kertalangu dan Pulau Serangan. Jenis data yang digunakan adalah kualitatif dan kuantitatif. Sedangkan untuk sumber data menggunakan data primer dan data sekunder. Pengumpulan data dilakukan dengan cara observasi, kuisioner dan studi kepustakaan. Teknik penentuan sampel secara aksidental dengan jumlah sampel sebanyak 100 orang mengacu pada rumus Slovin (Abubakar, 2009). Data hasil penelitian dianalisis secara deskriptif kualitatif.

\section{HASIL}

Karakteristik Wisatawan Nusantara yang Berkunjung ke Daya Tarik Wisata City Tour Denpasar

Karakteristik wisatawan nusantara yang berkunjung ke daya tarik wisata city tour Denpasar pada kelompok umur 15-30 tahun sebesar 81\%, umur 31-46 (10\%), dan umur 46 ke atas sebesar $9 \%$, berikutnya jenis kelamin laki-laki sebesar $60 \%$, dan perempuan $40 \%$, berikutnya yang berstatus menikah sebesar $21 \%$, dan belum menikah $79 \%$, berikutnya sekolah menengah pertama $4 \%$, sekolah menengah atas $22 \%$, diploma $3 \%$, dan sarjana $71 \%$, berikutnya yang bekerja sebagai pelajar/mahasiswa sebesar $77 \%$, pegawai swasta $15 \%$, pegawai negeri $5 \%$, dan wiraswasta $3 \%$, berikutnya yang berasal dari daerah Ambon 3\%, Papua 4\%, Flores 23\%, Sumba 3\%, Pontianak 1\%, Medan 3\%, Makassar 5\%, Lampung 1\%, Pulau Jawa 56\%, dan Kupang $1 \%$, berikutnya sumber informasi yang diperoleh dari travel agent sebesar 9\%, madia cetak $6 \%$, media elektronik $22 \%$, media sosial 24\%, teman atau keluarga $36 \%$, dan tourist information centre 3\%, berikutnya yang menggunakan mode transportasi udara sebesar $32 \%$, darat $62 \%$, dan kapal laut $6 \%$, berikutnya yang menggunakan jenis akomodasi hotel sebesar $65 \%$, home stay 3\%, teman/ keluarga $30 \%$, dan lain-lain $2 \%$, berikutnya frekuensi berkunjung 1 kali sebesar $13 \%$, 2-3 kali $75 \%$, 4 kali $2 \%$, dan $>4$ kali $10 \%$, berikutnya yang memilih berkunjung ke daya tarik wisata Kota Denpasar karena mudah dijangkau sebesar $45 \%$, menarik untuk dikunjungi $30 \%$, biaya lebih murah $10 \%$, belum pernah dikunjungi sebelumnya 15\%, dan kelengkapan fasilitas $5 \%$, berikutnya merupakan jenis kunjungan pertama sebesar $65 \%$, dan tidak $35 \%$, berikutnya orang yang diajak hanya diri sendiri sebesar $6 \%$, teman sekolah/ kantor 15\%, keluarga 12\%, rombongan travel agent $65 \%$, dan lain-ain $2 \%$ dan terakhir pengorganisir kunjungan wisata oleh diri sendiri sebesar $4 \%$, keluarga $13 \%$, sekolah $75 \%$, kantor $6 \%$, dan biro perjalanan atau travel agent $2 \%$.

\section{Motivasi Intrinsik Wisatawan Nusantara yang Berkunjung ke Daya Tarik Wisata City Tour Denpasar}

Motivasi instrinsik wisatawan nusantara yang berkunjung ke daya tarik wisata city tour di Denpasar menunjukan bahwa indikator motivasi instrinsik untuk mengetahui kesenian Bali baik berupa tarian, musik, dan arsitektur bangunan serta melakukan studi banding memiliki skor sebesar 4,21 (sangat kuat). Sedangkan, indikator motivasi instrinsik yang memiliki skor terendah adalah ingin menikmati alam 3,7 (kuat).

Selanjutnya, 12 indikator motivasi instrinsik lainnya memiliki skor pada rentang yang sama yaitu pada kategori sikap kuat secara berurutan adalah sebagai berikut mengetahui aktivitas keagamaan (Hindu) di Bali dengan skor 4,18 (kuat), gengsi/ dapat menceritakan ke orang lain dengan skor 4,15 (kuat), mengunjungi teman dan keluarga yang tinggal di Bali dengan skor 4,13 (kuat), ingin melakukan hal lain selain rutinitas dengan skor 4,12 (kuat), melihat-lihat (sight seeing) dan 
mengetahui sejarah Bali dengan skor 4,11 (kuat), bertemu dan berinteraksi dengan masyarakat lokal yang ditemui dengan skala 4,08 (kuat), mengetahui cerita rakyat Bali dengan skor 4,06 (kuat), ingin bersenangsenang dengan skor 4,01 (kuat), melakukan penelitian tentang objek wisata city tour di Denpasar dengan skor 4,00 (kuat), Menyalurkan hobi berjalan-jalan dengan skor 3,98 (kuat), mengetahui tradisi masyarakat Bali (cara berpakaian, pergaulan, gaya hidup) dengan skor 3,73 (kuat), dan yang terkahir adalah motivasi intrinsik dengan indikator ingin menikmati alam dengan skor 3,70 (kuat).

Berdasarkan hasil di atas maka diperoleh hasil bahwa motivasi intrinsik yang mendominasi adalah mengetahui kesenian Bali baik berupa tarian, musik, dan arsitektur bangunan dan melakukan studi banding. Jika dilihat lebih jauh, motivasi ini dapat menjadi motivasi intrinsik yang tertinggi jika dikaitkan dengan karakteristik yang mendominasi wisatawan nusantara pada penelitian ini adalah berumur 15-30 tahun dan didominasi oleh para pelajar yang datang berkunjung untuk melakukan studi banding guna mengetahui kebudayaan Bali.

Selanjutnya, analisis faktor dilakukan menggunakan 15 indikator/ variabel faktor pendorong motivasi intrinstik menunjukkan bahwa nilai determinant of correlation sebesar 0,00 . Nilai yang mendekati nol berarti bahwa variabel-variabel saling berhubungan. Selanjutnya, nilai uji Bartlett's Test of Sphericity sebesar 4756,178 yang berarti bahwa peluang kesalahan dukungan data variabel-variabel saling berhubungan adalah $0 \%$, artinya hubungan antara variabel adalah significant. Selanjutnya, nilai uji Kaiser Meyer Olkin (KMO) dalam penelitian ini sebesar $0,767(>0,5)$, artinya ada hubungan satu sama lain antara variabel. Selanjutnya, pada analisis faktor ini semua variabel memenuhi kriteria nilai uji Measure of Sampling Adequency (MSA) yakni sebanyak 15 variabel antara lain: ingin bersenang-senang, menikmati alam, melakukan hal lain,selain rutinitas, melihatlihat, mengetahui sejarah Bali, mengetahui kesenian Bali (tarian, musik dan arsitektur bangunan), mengetahui tradisi masyarakat Bali (cara berpakaian, pergaulan, gaya hidup), mengetahui aktivitas keagamaan (Hindu) di Bali, berkunjung ke daya tarik wisata untuk mengetahui cerita rakyat Bali, bertemu dan berinteraksi dengan masyarakat lokal yang ditemui, mengunjungi teman dan keluarga yang tinggal di Bali, gengsi atau dapat menceritakan ke orang lain, melakukan studi banding, melakukan penelitian tentang daya tarik wisata city tour di Denpasar dan menyalurkan hobi berjalan-jalan. Untuk interpretasi hasil penelitian ini, loading factor minimal adalah 0,4 sedangkan indikator yang mempunyai faktor kurang dari 0,4 dikeluarkan dari model.

\section{Motivasi Ekstrinsik Wisatawan Nusantara yang Berkunjung ke Daya Tarik Wisata City Tour Denpasar}

Motivasi ekstrinsik wisatawan nusantara yang berkunjung ke daya tarik wisata city tour di Denpasar menunjukan bahwa motivasi ektrinsik tertinggi adalah pada indikator biaya masuk daya tarik wisata yang dinilai cukup terjangkau dengan skor sebesar 4,2 yang berarti bahwa wisatawan nusantara secara ekstrinsik termotivasi oleh biaya masuk daya tarik wisata yang sangat terjangkau. Selanjutnya, motivasi ekstrinsik yang memiliki skor urutan kedua dan seterusnya adalah: keunikan dari daya tarik wisata ini sebesar 3,74 (kuat), telah dijadwalkan oleh sekolah / perusahaan / travel agent sebesar 3,65 (kuat), ajakan teman/ keluarga sebesar 3,57 (kuat), dan adanya waktu luang sebesar 3,43 (kuat). Sehingga dapat disimpulkan bahwa dari lima indikator motivasi ekstrinsik yang mendominasi motivasi ekstrinsik wisatawan nusantara yang berkunjung ke daya tarik wisata city tour di Denpasar adalah biaya masuk daya tarik yang sangat terjangkau bagi wisatawan nusantara, karena karakteristik yang mendominasi adalah pelajar yang belum memiliki penghasilan yang cukup untuk melakukan kunjungan ke daya tarik wisata dengan harga yang mahal.

Selanjutnua, analisis faktor dilakukan menggunakan 5 indikator/ variabel faktor pendorong motivasi ekstrinstik menunjukkan bahwa nilai determinant of correlation mendekati nol $(0,001)$ berarti variabelvariabel yang diidentifikasikan saling berhubungan. Selanjutnya, nilai uji Bartlett's Test of Sphericity adalah 639,413 yang berarti bahwa peluang kesalahan dukungan data yang menyatakan bahwa variabel-variabel saling berhubungan adalah $0 \%$ atau dengan kata lain hubungan antara variabel adalah significant. Selanjutnya, nilai uji Kaiser Meyer Olkin (KMO) sebesar 0,835 melewati batas 
minimum 0,5. Hal ini berarti bahwa variabel ada hubungan satu sama lain sehingga analisis faktor tepat digunakan dalam penelitian ini. Selanjutnya, pada analisis faktor ini semua variabel memenuhi kriteria nilai uji Measure of Sampling Adequency (MSA) yakni sebanyak 5 variabel antara lain: keunikan daya tarik wisata, biaya masuk daya tarik wisata yang sangat terjangkau, adanya waktu luang, ajakan teman/ keluarga, dan telah dijadwalkan oleh sekolah/ perusahaan/travel agent. Untuk interpretasi hasil penelitian ini, loading factor minimal adalah 0,4 sedangkan indikator yang mempunyai faktor kurang dari 0,4 dikeluarkan dari model.

\section{Kepuasan Wisatawan Nusantara yang Berkunjung ke Daya Tarik Wisata City Tour di Denpasar}

Kepuasan wisatawan nusantara yang berkunjung ke daya tarik wisata city tour di Denpasar menunjukan bahwa skor tertinggi terdapat pada indikator keramahan dan kesopanan petugas di daya tarik wisata city tour (sangat puas). Sedangkan indikator kepuasan yang memiliki skor terendah adalah Ketersediaan angkutan umum/ angkutan wisata menuju ke dan dari daya tarik wisata sebesar 3,9 (puas). Selanjutnya 14 indikator kepuasan wisatawan nusantara lainnya memiliki skor pada rentang yang sama yaitu puas. Dari hasil penghitungan skor, maka dapat diketahui bahwa indikator kepuasan wisatawan nusantara didominasi pada indikator non fisik berupa keramahan dan kesopanan petugas. Jika dianalisis secara menyeluruh, maka kategori sikap wisatawan berapa pada skala sangat puas dan puas, namun dari hasil skor tertinggi diberikan pada pelayanan yang diberikan di daya tarik wisata city tour yang dikunjungi.

Selanjutnya, analisis faktor dilakukan menggunakan 16 indikator/ variabel faktor pendorong kepuasan antara lain: variasi atraksi yang ada, keunikan atraksi yang ditawarkan, ketersediaan penunjuk arah menuju daya tarik wisata, ketersediaan angkutan wisata atau angkutan umum kendaraan dari daya tarik wisata, kelengkapan fasilitas yang mendukung aktivitas wisata, ketersediaan informasi mengenai daya tarik wisata, kebersihan area daya tarik wisata, kerapihan dan keteraturan penataan daya tarik wisata, ketersediaan informasi berupa peringatan atau anjuran mengenai daerah atau hal-hal yang berbahaya, kenyamanan dalam melakukan kegiatan berwisata, kenyamanan dalam penggunaan fasilitas yang disediakan (semua fasilitas dapat berfungsi sebagaimana mestinya), keamanan pada daya tarik wisata, keramahan dan kesopanan pelayanan oleh petugas yang berada pada daya tarik wisata, kemampuan petugas memberikan informasi mengenai daya tarik wisata city tour, kemampuan petugas dalam menangani keluhan, dan kesedian petugas dalam pemberian salam.

Nilai uji determinant of correlation mendekati nol yaitu sebesar 0,00 berarti bahwa variabel-variabel yang diidentifikasikan saling berhubungan. Selanjutnya, nilai uji Bartlett's Test of Sphericity adalah 3485,43 yang berarti peluang kesalahan dukungan data yang menyatakan variabel-variabel saling berhubungan adalah $0 \%$ atau hubungan antara variabel adalah significant. Selanjutnya, nilai uji Kaiser Meyer Olkin (KMO) sebesar 0,863 melewati batas minimum 0,5 . Hal ini berarti bahwa ada hubungan satu sama lain antara variabel sehingga analisis faktor tepat digunakan dalam penelitian ini. Selanjutnya, pada analisis faktor ini semua variabel memenuhi kriteria nilai uji Measure of Sampling Adequency (MSA) yakni sebanyak 16 variabel. Untuk interpretasi hasil penelitian ini, loading faktor minimal adalah 0,4 sedangkan indikator yang mempunyai faktor kurang dari 0,4 dikeluarkan dari model.

\section{PEMBAHASAN}

\section{Karakteristik Wisatawan Nusantara yang Berkunjung ke Daya Tarik Wisata City Tour Denpasar \\ Karakteristik wisatawan nusantara yang} berkunjung ke daya tarik wisata city tour Denpasar didominasi oleh kelompok umur 15$30 \%$, berikutnya jenis kelamin laki-laki $60 \%$, berikutnya status perkawinan belum menikah $79 \%$, berikutnya pendidikan universitas atau sarjana $71 \%$, berikutnya pekerjaan pelajar atau mahasiswa $77 \%$, berikutnya daerah asal Pulau Jawa $56 \%$, berikutnya sumber informasi teman atau keluarga $36 \%$, berikutnya mode transportasi darat $62 \%$, berikutnya jenis akomodasi hotel $65 \%$, berikutnya frekuensi berkunjung 2-3 kali 75\%, berikutnya memilih berkunjung ke daya tarik wisata Kota Denpasar mudah jangkau $45 \%$, berikutnya jenis kunjungan ya $65 \%$, berikutnya kelompok diajak rombongan travel agent $65 \%$, dan diorganisir sekolah $75 \%$. 
Faktor yang Mempengaruhi Motivasi Intrinsik Wisatawan Nusantara yang Berkunjung ke Daya Tarik Wisata City Tour Denpasar

Nilai loading factor indikator yang tertinggi dalam faktor motivasi intrinsik adalah indikator x1.1 (ingin bersenang-senang) sebesar 0,958 dan indikator terendah sebesar 0,853 adalah untuk mengetahui aktifitas keagamaan Hindu di Bali. Tingginya nilai loading factor pada indikator ingin bersenangsenang lebih dikarenakan untuk melepaskan diri dari rasa jenuh/bosan terhadap suatu kegiatan/rutinitas. Selain itu, atraksi wisata atau daya tarik wisata city tour di Kota Denpasar memiliki keunikan yang hanya ditemukan di tempat tersebut. Sedangkan, rendahnya nilai loading factor pada indikator untuk mengetahui aktifitas kegaamaan Hindu di Bali dikarenakan saat penelitian berlangsung tidak ada even aktifitas keagamaan Hindu. Alasan lainnya seperti jumlah kunjungan wisata yang lebih dari sekali dan kemiripan aktifitas keagamaan Hindu antar daerah di Bali serta informasi dari media yang didapatkan.

Faktor yang Mempengaruhi Motivasi Ekstrinsik Wisatawan Nusantara yang Berkunjung ke Daya Tarik Wisata City Tour Denpasar

Nilai loading factor tertinggi dalam indikator faktor motivasi ektrinsik adalah biaya masuk daya tarik wisata yang sangat terjangkau sebesar 0,953 dan indikator terendah sebesar 0,882 adalah indikator ajakan teman/ keluarga. Tingginya nilai loading factor pada indikator biaya masuk daya tarik wisata yang sangat terjangkau dikarenakan lebih dominan berasal dari kalangan siswa dan mahasiswa yang belum bisa memiliki penghasilan sendiri. Namun, rendahnya nilai loading factor pada indikator ajakan teman/ keluarga dikarenakan wisatawan telah dijadwalkan oleh sekolah/ perusahaan/ travel agent.

Faktor yang Mempengaruhi Kepuasan Wisatawan Nusantara yang Berkunjung ke Daya Tarik Wisata City Tour Denpasar

Nilai loading factor indikator yang tertinggi dalam faktor kepuasan adalah indikator kemampuan petugas dalam memberikan informasi mengenai daya tarik wisata city tour sebesar 0,964 . Sedangkan nilai loading factor indikator terendah dalam faktor kepuasan adalah keramahan dan kesopanan pelayanan oleh petugas yang berada pada objek wisata sebesar 0,877 . Tingginya nilai loading factor pada indikator kemampuan petugas dalam memberikan informasi mengenai daya tarik wisata city tour dikarenakan para wisatawan mendapatkan informasi lebih yang menambah wawasan dan pengetahuan. Sementara, rendahnya nilai loading factor pada indikator keramahan dan kesopanan pelayanan oleh petugas yang berada pada objek wisata dikarenakan keramahan dan kesopanan petugas akan membuat wisatawan lebih nyaman dalam menikmati kunjungannya. Secara keseluhan dapat disimpulkan bahwa nilai loading factor seluruh komponen faktor kepuasan lebih dari batas minimal dengan rentang nilai sebesar $0,877-0,964$ (puas).

\section{SIMPULAN DAN SARAN Simpulan}

Berdasarkan hasil dan pembahasan tentang karakteristik, motivasi dan kepuasan wisatawan nusantara yang berkunjung ke daya tarik wisata city tour Denpasar, maka dapat diambil simpulan sebagai berikut:

1. Karakteristik wisatawan nusantara yang berkunjung ke daya tarik wisata city tour Denpasar mayoritas didominasi jenis kelamin laki-laki, berusia 15-30 tahun, status perkawinan belum menikah, latar belakang pendidikan sarjana, berasal dari pulau Jawa dan memperoleh informasi dari tourist information centre dan teman atau keluarga.

2. Motivasi intirinsik dan motivasi ekstrinsik wisatawan nusantara yang berkunjug ke daya tarik wisata city tour Denpasar adalah mayoritas ingin mengetahui kesenian budaya seperti tarian, musik dan arsitektur bangunan Bali serta studi banding. Sedangkan motivasi ekstrinsik adalah mayoritas dikarenakan keterjangkauan biaya tiket masuk.

3. Kepuasan wisatawan nusantara yang berkunjung ke daya tarik wisata city tour Denpasar mayoritas terletak pada kepuasan terhadap faktor non fisik yaitu pada indikator keramahan dan kesopanan petugas pada daya tarik wisata city tour yang dikunjungi. Secara keseluruan kepuasan wisatawan baik pada daya tari yang bersifat fisik maupun non fisik 
terletak pada skala atau kategori sikap puas.

\section{Saran}

Berdasarkan simpulan hasil pembahasan tersebut, maka saran yang dapat diberikan sebagai berikut:

1. Sebaiknya pemerintah Kota Denpasar khususnya Dinas Pariwisata menyediakan satu paket wisata unik berupa miniatur tradisi masyarakat Bali di Kota Denpasar meliputi: tarian, musik, arsitektur bangunan dan peningalan purbakala.

2. Sebaiknya pemerintah Kota Denpasar meningkatkan fasilitas fisik setiap daya tarik wisata city tour dan memperhatikan ketersediaan angkutan wisata agar kepuasan wisatawan nusantara meningkat.

3. Sebaiknya pengelola daya tarik wisata city tour Denpasar menyusun inovasi keunikan paket wisata yang ditawarkan, memperhatikan kerapihan dan keteraturan penataan daya tarik serta kesediaan petugas dalam pemberian salam.

\section{DAFTAR PUSTAKA}

Abubakar. 2009. Persepsi terhadap Pengguna Transportasi Trans Jakarta. Tesis. Jakarta: Fisip. Universitas Indonesia.

Alaeddinoglu F. 2013. Basic Characteristics, Motivations, and Activities of Ecotourists: A Case of Lake Van Basin Area, Turkey. The Journal of Academic Social Science Studies Faculty of Arts and Literature, Department of Geography. Van. Turky.. No. 3 Vol. 6.

Dinas Pariwisata Kota Denpasar. 2014. Data Pariwisata Kota Denpasar. Denpasar: Dinas Pariwisata Kota Denpasar.

Menuh NN. 2015. Karakteristik Wisatawan Backpacker Mancanegara dan Dampaknya terhadap Perkembangan Pariwisata di Kuta, Bali. Tesis. Program Studi Kajian Pariwisata Program Pascasarjana Universitas Udayana: Denpasar.

Pitana IG dan PG Gayatri. 2005. Sosiologi Pariwisata. Yogyakarta: Penerbit ANDI.

Sugiyono. 2004. Metode Penelitian Bisnis. Bandung: Alfabeta.

Sari F. 2014. Tinjauan terhadap Motivasi Wisatawan Berkunjung ke Objek Wisata Air Terjun Aek Martua Kabupaten Rakon Hulu Propinsi Riau. Program
Studi Usaha Perjalanan Wisata. Fakultas Ilmu Sosial dan Ilmu Politik. Riau: Universitas Riau. 